\title{
Inguinal hernia repair: are the results from a general hospital comparable to those from dedicated hernia centres?
}

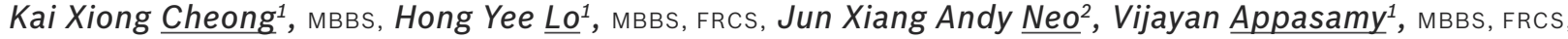
Ming Terk $\underline{\text { Chiu }}^{1}$, MBBS, FRCS

INTRODUCTION We aimed to report the outcomes of inguinal hernia repair performed at Tan Tock Seng Hospital and compare them with those performed at dedicated hernia centres.

METHODS We retrospectively analysed the medical records and telephone interviews of 520 patients who underwent inguinal hernia repair in 2010.

RESULTS The majority of the patients were male (498 [95.8\%] men vs. 22 [4.2\%] women). The mean age was $59.9 \pm 15.7$ years. Most patients $(n=445,85.6 \%)$ had unilateral hernias ( $25.8 \%$ direct, $64.3 \%$ indirect, $9.9 \%$ pantaloon). The overall recurrence rate was $3.8 \%$, with a mean time to recurrence of $12.0 \pm 8.6$ months. Risk factors for recurrence included contaminated wounds (odds ratio [OR] 50.325; $p=0.004)$, female gender (OR 8.757; $p=0.003)$ and pantaloon hernias (OR 5.059; $p=0.013)$. Complication rates were as follows: chronic pain syndrome $(1.2 \%)$, hypoaesthesia $(5.2 \%)$, wound dehiscence $(0.4 \%)$, infection $(0.6 \%)$, haematoma/seroma $(4.8 \%)$, urinary retention $(1.3 \%)$ and intraoperative visceral injury (0.6\%). Most procedures were open repairs (67.7\%), and laparoscopic repair constituted $32.3 \%$ of all the inguinal hernia repairs. Open repairs resulted in longer operating times than laparoscopic repairs (86.6 mins vs. 71.6 mins; $p<0.001$ ), longer hospital stays (2.7 days vs. 0.7 days; $p=0.020$ ) and a higher incidence of post-repair hypoaesthesia $(6.8 \%$ vs. $1.8 \% ; p=0.018)$. However, there were no significant differences in recurrence or other complications between open and laparoscopic repair.

CONCLUSION A general hospital with strict protocols and teaching methodologies can achieve inguinal hernia repair outcomes comparable to those of dedicated hernia centres.

Keywords: complications, inguinal hernia repair, laparoscopic, open, recurrence

\section{INTRODUCTION}

Inguinal hernia repair is a common operation, and the recurrence rate of inguinal hernia following primary repair has been reported to be $0.5 \%-10.0 \% .^{(1-4)}$ The reported rates of chronic pain $(0.7 \%-62.9 \%),{ }^{(5-7)}$ wound infection $(1.0 \%-$ $7.0 \%){ }^{(8)}$ urinary retention $(0.2 \%-22.2 \%){ }^{(9,10)}$ hypoaesthesia $(4.3 \%-67.0 \%)^{(11,12)}$ and other postoperative complications after hernia repair also extend over wide ranges. Such wide variations in incidences may be attributed to differences in patient factors (e.g. gender, age, comorbidities and the subjective perception of symptoms) and institutional factors (e.g. surgeon's experience, method of repair, type of anaesthesia and duration of follow-up).

In our centre, Tan Tock Seng Hospital, Singapore, a large general hospital with 1,500 inpatient beds, inguinal hernia repairs are undertaken by most teams in the general surgery service under both emergency and elective settings. At our centre, the Lichtenstein method, which uses a nonabsorbable mesh to achieve tension-free repair, is adopted for open hernia repair. Open hernia repairs are performed by surgeons of varying grades and experience, ranging from the most junior medical officer to the most experienced senior consultant. The totally extraperitoneal (TEP) and transabdominal preperitoneal
(TAPP) approaches are both undertaken for laparoscopic hernia repair. The TEP approach is preferred to the TAPP approach despite the steeper learning curve of the former. There is such a preference because the peritoneum is not entered in the TEP approach, thereby conferring a theoretically reduced risk of bowel injury. Only more senior surgeons perform laparoscopic hernia repair due to the steeper learning curve involved. Surgeons with less experience are proctored by senior surgeons before they operate independently.

Patients with bilateral and recurrent inguinal hernias are offered laparoscopic hernia repair, but for those with unilateral primary inguinal hernia, the choice of laparoscopic versus open hernia repair depends on the surgeon's experience and preference. However, almost all emergency hernia repairs are done using the open method. If there is bowel resection and significant contamination during surgery, the placement of a mesh is omitted to prevent implant infection. In such patients, the posterior abdominal wall is darned using nonabsorbable sutures. This is a method of continuous suturing with no tension to create a loose reticular network of suture material, over which fibrosis can take place to strengthen the abdominal wall.

In the present study, we sought to report our centre's experience in inguinal hernia repair over a one-year audit

Department of General Surgery, Tan Tock Seng Hospital, ${ }^{2}$ Yong Loo Lin School of Medicine, National University of Singapore, Singapore

Correspondence: Dr Cheong Kai Xiong, House Officer, Department of General Surgery, Tan Tock Seng Hospital, 11 Jalan Tan Tock Seng, Singapore 308433. kaixiong.cheong@mohh.com.sg 
period. We expected dedicated hernia centres to report better recurrence and complication rates than general hospitals. For instance, the Lichtenstein Hernia Institute, United States, and the Shouldice Hospital, Canada, have reported recurrence rates of $0.1 \%{ }^{(13,14)}$ and less than $1 \%,{ }^{(15,16)}$ respectively, following hernia repair. Although our centre is a large tertiary hospital that is designed to attend to a large population with a myriad of ailments, and is not a dedicated hernia centre, we hypothesised that any general hospital (such as ours) with a high volume of patients, good audit and training practices, and sound teaching methodologies for surgical trainees will also be able to achieve respectable surgery outcomes.

The primary objective of this study was to compare the hernia recurrence rate at our centre against published data, especially data from dedicated hernia centres. Our secondary objectives include the following: (a) to identify possible predictive factors of hernia recurrence; (b) to report the incidence of postoperative complications after hernia repair such as chronic pain, hypoaesthesia, wound dehiscence, infection, haematoma/ seroma, urinary retention and intraoperative visceral injury; and (c) to compare the outcomes of open and laparoscopic inguinal hernia repairs.

\section{METHODS}

We performed a retrospective review of all patients who underwent inguinal hernia repair at our centre from 1 January to 31 December 2010. Elective and emergency surgeries, laparoscopic and open hernia repairs, primary and recurrent hernia repairs, and unilateral and bilateral hernia repairs were included in our study. Patients treated in the year 2010 were chosen for this study so that, at the time of audit, all participants would have been followed up for at least one year after hernia repair, thus providing sufficient time to assess for recurrence and establish whether complications such as operative site pain and/or numbness were chronic. We excluded patients who had incomplete surgical or follow-up data, or who died from causes unrelated to inguinal hernia or the hernia repair operation.

The medical records of all patients were reviewed, and data on patient demographics, hernia characteristics, management details, recurrence rate and complications after hernia repair (e.g. chronic pain, hypoaesthesia, wound dehiscence, infection, haematoma/seroma, urinary retention and intraoperative visceral injury) were collected. To improve the accuracy of results, standardised telephone interviews were conducted to assess patient satisfaction and to document any possible postoperative complication that might have been missed in the medical records. The telephone interviews also served to include patients who might have sought treatment at other hospitals for their complications, as well as those who may have selfmedicated for minor ailments. To improve response rate, two attempts were made to contact all patients. We decided against using standardised quality of life questionnaires, as they were difficult to administer over the telephone, especially for patients who did not speak English. Instead, we opted to simply ask patients whether they were satisfied with the operation and whether they would recommend the operation should their family members and friends develop inguinal hernias. Ethical approval for the study was obtained from the institutional review board.

Chronic postoperative pain after hernia repair was defined as pain or discomfort that persisted for three months or more following the surgery. ${ }^{(17)}$ We also evaluated factors postulated to influence the recurrence of hernia, which include gender, age, body mass index (BMI), smoking history, hernia type, urgency of operation, grade of surgeon, surgical technique and wound contamination. Asian-specific BMI standards (underweight: $<18.5 \mathrm{~kg} / \mathrm{m}^{2}$; ideal weight: $18.5-22.9 \mathrm{~kg} / \mathrm{m}^{2}$; overweight: $\geq 23.0 \mathrm{~kg} / \mathrm{m}^{2}$ ) were used in our study. ${ }^{(18)}$ The outcomes of open hernia repair were compared against that of laparoscopic hernia repair.

Data was analysed using IBM SPSS Statistics for Windows version 19.0 (IBM Corp, Armonk, NY, USA). Normality of quantitative data was ascertained using the quantile-quantile plot. Differences among the various groups were tested using Pearson's chi-square test, Fisher's exact test and independent samples $t$-test, where appropriate. Multiple logistic regression analyses were performed to identify factors that significantly influenced hernia recurrence.

\section{RESULTS}

After excluding 41 patients from the total number of patients surveyed ( $\mathrm{n}=561$ ), 520 patients were included in the study. The reasons for exclusion were incomplete surgical or followup data $(\mathrm{n}=31)$, and death by causes unrelated to inguinal hernia or hernia repair $(n=10)$. The majority of the patients included in the study were men $(n=498,95.8 \%)$, while women made up $4.2 \%(n=22)$ of the cohort. Most of the patients were Chinese $(n=398,76.5 \%)$. The mean age of the patients was $59.9 \pm 15.7$ (range 19-90) years. Approximately half of the patients were overweight. The majority of the patients were current or previous smokers (83.3\%). The patient characteristics are summarised in Table I.

Most of our patients (85.6\%) presented with unilateral inguinal hernia. Among patients with unilateral inguinal hernia, the most common form observed was indirect hernia (64.3\%). Overall, $77.9 \%$ of otherwise asymptomatic patients presented with a lump, and only $0.8 \%$ of patients presented with strangulation. The characteristics of the inguinal hernias observed in our patients are summarised in Table II.

The majority of inguinal hernia repairs were elective procedures $(89.6 \%)$, and $58.1 \%$ of inguinal hernia repairs were performed by surgeons at the level of associate consultant and above. The methods of repair included open mesh $(64.8 \%)$, open non-mesh $(2.9 \%)$, TEP $(30.8 \%)$ and TAPP $(1.5 \%)$. In terms of wound contamination, the majority of the operations 
Table I. Characteristics of patients included in the study $(n=520)$.

\begin{tabular}{|c|c|}
\hline Characteristic & No. (\%) \\
\hline \multicolumn{2}{|l|}{ Gender } \\
\hline Male & 498 (95.8) \\
\hline Female & $22(4.2)$ \\
\hline Age at diagnosis* (yrs) & $59.9 \pm 15.7(19-90)$ \\
\hline \multicolumn{2}{|l|}{ Ethnicity } \\
\hline Chinese & 398 (76.5) \\
\hline Malay & $53(10.2)$ \\
\hline Indian & $42(8.1)$ \\
\hline Other $^{+}$ & $27(5.2)$ \\
\hline \multicolumn{2}{|l|}{ Body mass index $\left(\mathrm{kg} / \mathrm{m}^{2}\right)$} \\
\hline$<18.5$ & $42(8.1)$ \\
\hline $18.5-22.9$ & $217(41.7)$ \\
\hline$\geq 23.0$ & $261(50.2)$ \\
\hline Overall* & $22.7 \pm 3.4(14.5-35.9)$ \\
\hline \multicolumn{2}{|l|}{ Diabetes mellitus } \\
\hline Yes & 69 (13.3) \\
\hline No & $451(86.7)$ \\
\hline \multicolumn{2}{|l|}{ Smoking } \\
\hline Yes & $126(24.2)$ \\
\hline No & $87(16.7)$ \\
\hline Prior history & $307(59.0)$ \\
\hline No. of pack years* & $24.8 \pm 21.7(1-120)$ \\
\hline \multicolumn{2}{|l|}{ ASA grade } \\
\hline 1 & $71(13.7)$ \\
\hline II & $364(70.0)$ \\
\hline III & $83(16.0)$ \\
\hline IV & $2(0.4)$ \\
\hline \multicolumn{2}{|l|}{ Patient category } \\
\hline Private & 145 (27.9) \\
\hline Subsided & $375(72.1)$ \\
\hline
\end{tabular}

* Data is presented as mean \pm standard deviation (range). ${ }^{\dagger}$ Includes Eurasians, Sikhs and Caucasians. ASA: American Society of Anesthesiologists

Table II. Characteristics of inguinal hernia in our patients $(n=520)$.

\begin{tabular}{lc}
\hline Characteristic & No. (\%) \\
\hline Side of inguinal hernia & \\
$\quad$ Right & $250(48.1)$ \\
Left & $195(37.5)$ \\
$\quad$ Bilateral & $75(14.4)$ \\
Type of unilateral hernia ( $\mathbf{n}=\mathbf{4 4 5 )}$ & \\
$\quad$ Direct & $115(25.8)$ \\
Indirect & $286(64.3)$ \\
Pantaloon & $44(9.9)$ \\
Episode & \\
Primary & $491(94.4)$ \\
Recurrent & $29(5.6)$ \\
Presentation & \\
Lump & $405(77.9)$ \\
Lump and pain & $48(9.2)$ \\
Lump, pain and incarceration & $63(12.1)$ \\
Lump, pain and strangulation & $4(0.8)$ \\
\hline
\end{tabular}

performed were classified as clean (95.4\%). Only $3(0.6 \%)$ patients had intraoperative complications - injury to spermatic cord structures $(n=1)$, injury to the ilioinguinal nerve $(n=1)$ and injury to the large colon $(n=1)$. Details of the inguinal hernia repairs performed during the study period are summarised in Table III.

The most common postoperative complication after hernia repair was hypoaesthesia (5.2\%). Other complications
Table III. Characteristics of inguinal hernia repairs performed during the study period $(n=520)$.

\begin{tabular}{|c|c|}
\hline Variable & No. (\%) \\
\hline $\begin{array}{l}\text { Urgency of operation } \\
\text { Elective } \\
\text { Emergency }\end{array}$ & $\begin{array}{r}466(89.6) \\
54(10.4)\end{array}$ \\
\hline $\begin{array}{l}\text { Grade of surgeon } \\
\text { Senior consultant } \\
\text { Consultant } \\
\text { Associate consultant } \\
\text { Registrar } \\
\text { Medical officer }\end{array}$ & $\begin{array}{c}47(9.0) \\
216(41.5) \\
39(7.5) \\
170(32.7) \\
48(9.2)\end{array}$ \\
\hline $\begin{array}{l}\text { Hernia repair technique } \\
\text { Open mesh } \\
\text { Open non-mesh } \\
\text { Totally extraperitoneal } \\
\text { Transabdominal pre-peritoneal }\end{array}$ & $\begin{aligned} 337 & (64.8) \\
15 & (2.9) \\
160 & (30.8) \\
8 & (1.5)\end{aligned}$ \\
\hline $\begin{array}{l}\text { Wound contamination } \\
\text { Clean } \\
\text { Clean-contaminated } \\
\text { Contaminated }\end{array}$ & $\begin{array}{r}496(95.4) \\
21(4.0) \\
3(0.6)\end{array}$ \\
\hline $\begin{array}{l}\text { Contents of sac } \\
\text { Empty } \\
\text { Omentum } \\
\text { Viable bowel } \\
\text { Omentum and viable bowel } \\
\text { Gangrenous bowel } \\
\text { Bladder } \\
\text { Testes }\end{array}$ & $\begin{aligned} 308 & (59.2) \\
97 & (18.7) \\
75 & (14.4) \\
29 & (5.6) \\
7 & (1.3) \\
2 & (0.4) \\
2 & (0.4)\end{aligned}$ \\
\hline $\begin{array}{l}\text { Conversion from laparoscopic to } \\
\text { open herniorrhaphy }(n=168) \\
\text { Yes } \\
\text { No }\end{array}$ & $\begin{aligned} 5 & (3.0) \\
163 & (97.0)\end{aligned}$ \\
\hline $\begin{array}{l}\text { Intraoperative complication } \\
\text { None } \\
\text { Injury to spermatic cord structures } \\
\text { Injury to neurovascular structures } \\
\text { Injury to colon }\end{array}$ & $\begin{aligned} 517 & (99.4) \\
1 & (0.2) \\
1 & (0.2) \\
1 & (0.2)\end{aligned}$ \\
\hline Length of operation* (mins) & $80.4 \pm 32.4(15-220)$ \\
\hline Length of hospital stay* (days) & $2.1 \pm 9.1(0-141)$ \\
\hline
\end{tabular}

* Data is presented as mean \pm standard deviation (range).

Table IV. Outcomes of patients who underwent inguinal hernia repair $(n=520)$.

\begin{tabular}{lcr}
\hline \multirow{2}{*}{ Variable } & \multicolumn{2}{c}{ No. (\%) } \\
\cline { 2 - 3 } & \multicolumn{1}{c}{ Yes } & \multicolumn{1}{c}{ No } \\
\hline Recurrence of inguinal hernia & $20(3.8)$ & $500(96.2)$ \\
Reoperation for recurrence $(\mathbf{n}=\mathbf{2 0 )}$ & $15(75.0)$ & $5(25.0)$ \\
Postoperative complication & & \\
$\quad$ Hypoaesthesia & $27(5.2)$ & $493(94.8)$ \\
Haematoma/seroma & $25(4.8)$ & $495(95.2)$ \\
Urinary retention & $7(1.3)$ & $513(98.7)$ \\
Chronic pain & $6(1.2)$ & $514(98.8)$ \\
Wound infection & $3(0.6)$ & $517(99.4)$ \\
Intraoperative visceral injury & $3(0.6)$ & $517(99.4)$ \\
Wound dehiscence & $2(0.4)$ & $518(99.6)$ \\
\hline
\end{tabular}

observed were haematoma/seroma $(4.8 \%)$, urinary retention $(1.3 \%)$, chronic pain syndrome $(1.2 \%)$, infection $(0.6 \%)$, intraoperative visceral injury $(0.6 \%)$ and wound dehiscence $(0.4 \%)$. Hernia recurrences occurred in 20 (3.8\%) patients. Overall, the mean time to hernia recurrence was found to be $12.0 \pm 8.6(0.2-29.0)$ months. The outcomes of inguinal hernia repair are summarised in Table IV. 
Table V. Univariate analysis of factors influencing hernia recurrence.

\begin{tabular}{|c|c|c|c|}
\hline \multirow[t]{2}{*}{ Variable } & \multicolumn{2}{|c|}{ No. (\%) } & \multirow[t]{2}{*}{ p-value } \\
\hline & Recurrence & $\begin{array}{c}\text { No } \\
\text { recurrence }\end{array}$ & \\
\hline Gender & & & $0.007^{+}$ \\
\hline Male & $16(3.2)$ & $482(96.8)$ & \\
\hline Female & $4(18.2)$ & $18(81.8)$ & \\
\hline Age $^{*}$ (yrs) & $60.6 \pm 17.5$ & $59.9 \pm 15.6$ & NS \\
\hline Body mass index $\left(\mathrm{kg} / \mathrm{m}^{2}\right)$ & & & NS \\
\hline$<18.5(n=42)$ & $2(4.8)$ & $40(95.2)$ & \\
\hline $18.5-22.9(n=217)$ & $7(3.2)$ & $210(96.8)$ & \\
\hline$\geq 23.0(n=261)$ & $11(4.2)$ & $250(95.8)$ & \\
\hline Smoking & & & NS \\
\hline Yes $(n=126)$ & $5(4.0)$ & $121(96.0)$ & \\
\hline No $(n=87)$ & $3(3.4)$ & $84(96.6)$ & \\
\hline Prior history $(n=307)$ & $12(3.9)$ & $295(96.1)$ & \\
\hline No. of pack years ${ }^{*}$ & $23.9 \pm 12.7$ & $24.9 \pm 21.9$ & NS \\
\hline Patient category & & & NS \\
\hline Private $(n=145)$ & $6(4.1)$ & $139(95.9)$ & \\
\hline Subsidised $(n=375)$ & $15(4.0)$ & $360(96.0)$ & \\
\hline Side of hernia & & & NS \\
\hline Right $(n=250)$ & $5(2.0)$ & $245(98.0)$ & \\
\hline Left $(n=195)$ & $9(4.6)$ & $186(95.4)$ & \\
\hline Bilateral $(n=75)$ & $5(6.7)$ & $70(93.3)$ & \\
\hline Type of unilateral hernia & & & $0.040^{+}$ \\
\hline Direct $(n=115)$ & $4(3.5)$ & $111(96.5)$ & \\
\hline Indirect $(n=286)$ & $6(2.1)$ & $280(97.9)$ & \\
\hline Pantaloon $(n=44)$ & $4(9.1)$ & $40(90.9)$ & \\
\hline Urgency of operation & & & NS \\
\hline Elective $(n=466)$ & $17(3.6)$ & 449 (96.4) & \\
\hline Emergency $(n=54)$ & $3(5.6)$ & $51(94.4)$ & \\
\hline Grade of surgeon & & & NS \\
\hline $\begin{array}{l}\text { Associate consultant } \\
\text { and above }{ }^{\S}(n=302)\end{array}$ & $13(4.3)$ & $289(95.7)$ & \\
\hline $\begin{array}{l}\text { Medical officer and } \\
\text { registrar }(n=218)\end{array}$ & $7(3.2)$ & $211(96.8)$ & \\
\hline Hernia repair technique & & & NS \\
\hline Open $(n=352)$ & $13(3.7)$ & 339 (96.3) & \\
\hline Laparoscopic $(n=168)$ & $7(4.2)$ & $161(95.8)$ & \\
\hline Wound contamination & & & $0.019^{+}$ \\
\hline $\begin{array}{l}\text { Non-contaminated } \\
(\mathrm{n}=517)\end{array}$ & $19(3.7)$ & $498(96.3)$ & \\
\hline Contaminated $(n=3)$ & 1 (33.3) & $2(66.7)$ & \\
\hline
\end{tabular}

${ }^{*}$ For continuous variables, independent samples $t$-test was used to test for association. For categorical variables, Pearson's chi-square test and Fisher's exact test were used, where appropriate, to test for association. ${ }^{\dagger} \mathrm{p}<0.05$ was considered statistically significant. ${ }^{*} \mathrm{D}$ ata is presented as mean \pm standard deviation. ${ }^{\S}$ Associate consultant, consultant and senior consultant. NS: not significant

The risk factors for recurrence were contaminated wounds (odds ratio [OR] 50.325; $\mathrm{p}=0.004$ ), female gender (OR 8.757; $p=0.003$ ) and pantaloon hernias (OR 5.059; $\mathrm{p}=0.013)$. Other factors such as age, BMI, smoking status, patient category (i.e. private or subsidised), side of inguinal hernia, urgency of operation, grade of surgeon and hernia repair technique used were found to be insignificant. The findings of the univariate and multivariate analyses of factors influencing inguinal hernia recurrence in our patients are summarised in Tables $\mathrm{V}$ and $\mathrm{VI}$, respectively.

The responses of the patients to the telephone interviews showed that many of them were satisfied with the results of the inguinal hernia repair $(71.3 \%)$, and would recommend family
Table VI. Multivariate analysis of factors influencing hernia recurrence.

\begin{tabular}{lcc}
\hline Variable & OR (95\% Cl) & p-value \\
\hline $\begin{array}{l}\text { Gender } \\
\text { Female } \\
\text { Male* }\end{array}$ & $0.757(2.067-37.101)$ & \\
$\begin{array}{l}\text { Side of hernia } \\
\text { Bilateral }\end{array}$ & $\mathrm{NS}$ \\
$\quad$ Non-bilateral & $2.827(0.834-9.579)$ & \\
$\begin{array}{l}\text { Type of unilateral hernia } \\
\quad \text { Pantaloon } \\
\text { Non-pantaloon* }\end{array}$ & $5.059(1.408-18.186)$ & $0.013^{+}$ \\
$\begin{array}{l}\text { Wound contamination } \\
\text { Contaminated } \\
\text { Non-contaminated }\end{array}$ & $50.325(3.509-121.768)$ & \\
\hline
\end{tabular}

${ }^{*}$ Reference variable. ${ }^{\dagger} p<0.05$ was considered statistically significant OR: odds ratio; $\mathrm{Cl}$ : confidence interval; NS: not significant

Table VII. Characteristics pertaining to open and laparoscopic hernia repairs.

\begin{tabular}{|c|c|c|c|}
\hline \multirow[t]{2}{*}{ Characteristic } & \multicolumn{2}{|c|}{ No. (\%) } & \multirow[t]{2}{*}{ p-value* } \\
\hline & $\begin{array}{l}\text { Open hernia } \\
\text { repair }\end{array}$ & $\begin{array}{l}\text { Laparoscopic } \\
\text { hernia repair }\end{array}$ & \\
\hline ASA grade & & & $0.001^{+}$ \\
\hline I and II (n = 435) & $281(64.6)$ & $154(35.4)$ & \\
\hline III and IV $(n=85)$ & 71 (83.5) & $14(16.5)$ & \\
\hline $\begin{array}{l}\text { Incarceration/ } \\
\text { strangulation at } \\
\text { presentation }\end{array}$ & & & $<0.001^{\dagger}$ \\
\hline Yes $(n=67)$ & $63(94.0)$ & $4(6.0)$ & \\
\hline No $(n=453)$ & $289(63.8)$ & $164(36.2)$ & \\
\hline Urgency of operation & & & $<0.001^{+}$ \\
\hline Elective $(n=466)$ & $300(64.4)$ & $166(35.6)$ & \\
\hline Emergency $(n=54)$ & 52 (96.3) & $2(3.7)$ & \\
\hline
\end{tabular}

*For continuous variables, independent samples $t$-test was used to test fo association. For categorical variables, Pearson's chi-square test and Fisher's exact test were used, where appropriate, to test for association. ${ }^{\dagger} p<0.05$ was considered statistically significant.

ASA: American Society of Anesthesiologists

members $(94.7 \%)$ or friends $(95.6 \%)$ to undergo the operation should they develop inguinal hernias.

Table VII lists the characteristics pertaining to the open and laparoscopic hernia repairs in the present study. For patients with ASA grades III/IV, incarcerated/strangulated hernias and in emergency cases, open hernia repair was more likely to be performed than laparoscopic hernia repair $(83.5 \%$ vs $16.5 \%$, $p=0.001 ; 94.0 \%$ vs. $6.0 \%, p<0.001$; and $96.3 \%$ vs $3.7 \%$, $\mathrm{p}<0.001$, respectively). All laparoscopic hernia repairs were performed by surgeons at the level of associate consultant and above $(100.0 \%)$, whereas open hernia repairs were more commonly performed by medical officers and registrars (61.9\%), with the remaining $38.1 \%$ of open hernia repairs performed by surgeons at the level of associate consultant and above.

Open hernia repair was associated with a longer operating time than laparoscopic hernia repair (86.6 mins vs 71.6 mins; $p<0.001$ ). Likewise, open hernia repair was also associated with a longer hospital stay than laparoscopic hernia repair (2.7 days vs 0.7 days; $p=0.020$ ). A higher incidence of hypoaesthesia after hernia repair was seen in patients who underwent open hernia repair than in those who underwent laparoscopic hernia 
Table VIII. Comparison of the outcomes of open and laparoscopic hernia repairs.

\begin{tabular}{|c|c|c|c|}
\hline \multirow[t]{2}{*}{ Variable } & \multicolumn{2}{|c|}{ No. (\%) } & \multirow[t]{2}{*}{ p-value } \\
\hline & $\begin{array}{l}\text { Open hernia } \\
\text { repair } \\
(n=352)\end{array}$ & $\begin{array}{l}\text { Laparoscopic } \\
\text { hernia repair } \\
\quad(n=168)\end{array}$ & \\
\hline $\begin{array}{l}\text { Length of operation* } \\
\text { (mins) }\end{array}$ & $86.6 \pm 30.3$ & $71.6 \pm 34.4$ & $<0.001^{+}$ \\
\hline $\begin{array}{l}\text { Length of hospital stay* } \\
\text { (days) }\end{array}$ & $2.7 \pm 10.9$ & $0.7 \pm 0.8$ & $0.020^{+}$ \\
\hline $\begin{array}{l}\text { Hernia recurrence } \\
\text { Yes } \\
\text { No }\end{array}$ & $\begin{array}{c}13(3.7) \\
339(96.3)\end{array}$ & $\begin{aligned} 7 & (4.2) \\
161 & (95.8)\end{aligned}$ & NS \\
\hline $\begin{array}{l}\text { Time to recurrence* } \\
\text { (mths) }\end{array}$ & $11.7 \pm 9.7$ & $12.6 \pm 6.6$ & NS \\
\hline $\begin{array}{l}\text { Chronic pain } \\
\text { Yes } \\
\text { No }\end{array}$ & $\begin{array}{c}6(1.7) \\
346(98.3)\end{array}$ & $\begin{array}{c}0(0.0) \\
168(100.0)\end{array}$ & NS \\
\hline $\begin{array}{l}\text { Hypoaesthesia } \\
\text { Yes } \\
\text { No }\end{array}$ & $\begin{array}{c}24(6.8) \\
328(93.2)\end{array}$ & $\begin{array}{c}3(1.8) \\
165(98.2)\end{array}$ & $0.018^{+}$ \\
\hline $\begin{array}{l}\text { Wound dehiscence } \\
\text { Yes } \\
\text { No }\end{array}$ & $\begin{aligned} 1 & (0.3) \\
351 & (99.7)\end{aligned}$ & $\begin{array}{c}1(0.6) \\
167(99.4)\end{array}$ & NS \\
\hline $\begin{array}{l}\text { Wound infection } \\
\text { Yes } \\
\text { No }\end{array}$ & $\begin{array}{c}3(0.9) \\
349(99.1)\end{array}$ & $\begin{array}{c}0(0.0) \\
168(100.0)\end{array}$ & NS \\
\hline $\begin{array}{l}\text { Haematoma/seroma } \\
\text { Yes } \\
\text { No }\end{array}$ & $\begin{array}{c}19(5.4) \\
333(94.6)\end{array}$ & $\begin{array}{c}6(3.6) \\
162(96.4)\end{array}$ & NS \\
\hline $\begin{array}{l}\text { Urinary retention } \\
\text { Yes } \\
\text { No }\end{array}$ & $\begin{aligned} 5 & (1.4) \\
347 & (98.6)\end{aligned}$ & $\begin{aligned} 2 & (1.2) \\
166 & (98.8)\end{aligned}$ & NS \\
\hline
\end{tabular}

${ }^{*}$ For continuous variables, independent samples t-test was used to test for association. For categorical variables, Pearson's chi-square test and Fisher's exact test were used, where appropriate, to test for association. ${ }^{\dagger} p<0.05$ was considered statistically significant. ${ }^{\ddagger}$ Data is presented as mean \pm standard deviation. NS: not significant

repair $(6.8 \%$ vs $1.8 \% ; p=0.018)$. With respect to recurrence or other complications, there was no significant difference found between patients who underwent open hernia repair and those who underwent laparoscopic hernia repair. Table VIII compares the outcomes of open and laparoscopic hernia repairs.

\section{DISCUSSION}

Our results suggest that a general hospital with high patient volume, and good training and audit practices, is able to produce excellent results following inguinal hernia repair. We also found the level of patient satisfaction among those who underwent inguinal hernia repair to be high. However, the incidence of inguinal hernia recurrence at our centre was not as low as that reported by dedicated hernia centres such as the Lichtenstein Hernia Institute and Shouldice Hospital. We propose that this difference is due to the disparity in patient volumes between our centre and dedicated hernia centres. Surgeons at dedicated hernia centres typically perform in excess of 1,000 inguinal hernia repairs annually, and as repetition minimises variations and errors during inguinal hernia repair, higher patient volumes would give rise to the consistently low recurrence and complication rates found in the literature from these centres.

We are of the opinion that surgeons working in general hospitals could reorganise their services such that only designated surgeons perform inguinal hernia repairs. This would help to augment these surgeons' experience. Clinical services could also be reorganised to mirror those found at dedicated hernia centres - this may include preoperative screening for known predisposing patient factors such as chronic cough, chronic constipation and bladder outlet obstruction. Our centre has a preadmission assessment, counselling and evaluation (PACE) clinic that screens patients for medical comorbidities and provides verbal and written advice on preoperative instructions, anaesthetic and surgical risk, and postoperative pain management, prior to surgery. Useful paraclinical services after inguinal hernia repair include postoperative physiotherapy, and education on how to straighten the abdominal wall and promote avoidance of excessive weight lifting following surgical procedures. Coupled with strict protocols and teaching methodologies, the implementation of such measures may potentially push the recurrence and complication rates of general hospitals closer to that of specialised centres.

Several factors that influence the recurrence of inguinal hernias were identified in our study. These included contaminated wounds, female gender and pantaloon hernia. However, other factors such as BMI, smoking status, urgency of the operation, grade of the surgeon and hernia repair technique were not found to be significant. A higher recurrence rate in patients with contaminated wounds is relatively intuitive. Similarly, patients with pantaloon hernias are known to be at risk of developing recurrent hernias. ${ }^{(19)}$ Hence, the higher recurrence rate seen in patients with pantaloon hernias was not altogether surprising. However, we were unable to explain the higher recurrence rate associated with the female gender in our cohort. In a previous study, a U-shaped association between BMI and postoperative complications after hernia repair was found - patients with ideal weight showed the lowest risk, whereas patients who were either underweight or overweight/obese showed an increased risk. ${ }^{(20)}$ Although a $U$-shaped relationship was also observed in our study, the relationship between postoperative complications and BMI was not significant. Also, other risk factors usually suspected of influencing recurrence were not found to have any association with recurrence in our study.

Contrary to the findings of our study, two other studies have reported smoking as a risk factor for inguinal hernia recurrence. ${ }^{(21,22)}$ However, as compared to our study, these studies had longer follow-up periods and higher recurrence rates of $11.2 \%{ }^{(21)}$ and $7.7 \%^{(22)}$ over two- and ten-year periods, respectively. It is possible that the postulated effects of smoking - decreasing collagen biosynthesis and deposition, increasing proteolysis and thereby decreasing the tensile strength of wounds - need extended study periods to determine clinical significance. Due to our study's relatively shorter follow-up 
period and the possible subclinical nature of some inguinal hernia recurrences among our patients, we cannot disregard the possibility that the insignificant relationship between smoking and recurrence found in our study is an underestimation of the relationship between these variables.

With respect to open and laparoscopic inguinal hernia repairs in our study, we found that the seniority of surgeons was not a significant factor for hernia recurrence. This finding is in contrast to the findings of a study by Neumayer et al, which described inexperience in laparoscopic inguinal hernia repairs to be a risk factor for recurrence. ${ }^{(23)}$ A possible explanation for our finding is that a surgeon's grade may not reflect the number of hernia repairs performed. Indeed, some surgeons at the medical officer level at our centre are employed as permanent resident surgeons and do not progress along the usual track of specialist training hierarchy. It is therefore possible that surgeons with lower seniority may have performed more inguinal hernia repairs than surgeons at the level of registrar or even consultant. On the other hand, for laparoscopic hernia repairs at our centre, less-experienced surgeons are closely proctored by senior surgeons, thus accounting for the lack of difference in recurrence rates observed in our study.

For postoperative complications following hernia repair, the rates for chronic pain and numbness were included, although these two variables are not commonly reported in Asian institutions, where cultural influences may result in an under-reporting of pain and numbness. ${ }^{(24)}$ In our study, hypoaesthesia or numbness $(5.2 \%)$ was the most common postoperative complication following hernia repair. Despite this, a majority of our patients were satisfied with the surgery and would recommend the procedure to their families and friends, indicating that hypoaesthesia was not considered a major problem.

We were unable to demonstrate a difference in recurrence rates between patients who underwent laparoscopic hernia repair and those who underwent open hernia repair. This may primarily be attributed to the retrospective nature of our study. In contrast to our finding, a recent meta-analysis found TEP to be associated with a higher recurrence rate when compared to open hernia repairs. ${ }^{(25)}$ In previous studies, ${ }^{(6,26)}$ intraoperative complications were found to be more frequent in patients who underwent laparoscopic inguinal hernia repair when compared to open procedures. However, our sample size was too small to determine any difference between the two groups. In our study, operating time was shorter among patients who underwent laparoscopic hernia repair, even after adjusting for unilateral and bilateral hernia repair times. It is usual for laparoscopic hernia repair to take longer than its open equivalent. The disparity in our results (in spite of seniority not having a significant influence on hernia recurrence in our study) may be accounted for by the difference in the seniority of surgeons performing these operations, as laparoscopic hernia repairs were entirely performed by surgeons at the level of associate consultant and above. We found that following hernia repair, more patients in the open hernia repair group experienced postoperative hypoaesthesia than those in the laparoscopy group. However, there were no significant differences in the incidence of chronic pain or other postoperative complications in our patients, which is fairly consistent with other studies. ${ }^{(6,26)}$

There are several advantages and disadvantages to our study. One of the strengths of our study was that data was sourced from a general hospital and not a dedicated hernia centre, which many patients may not have easy access to. Our results highlight the need to improve the outcomes of inguinal hernia repairs performed in general hospitals. Our findings on chronic pain and hypoaesthesia among patients who underwent inguinal hernia repairs are novel, as these parameters are not commonly described in Asian populations. Moreover, our review of the patients' medical records was supplemented with telephone interviews to enhance the accuracy of our results. Our results highlight that the recording of centre-specific data, as well as the analysis of patient management and outcomes, is critical if surgery services at general hospitals are to progress and become more evidence-based.

A key limitation of our study was the retrospective nature of the audit. While we could establish associations between certain factors, we were unable to comment on the causal relationships between them. The relatively low response rates obtained for the telephone interviews in our study may also have led to an underestimation of complications, such as chronic pain and hypoaesthesia, in our cohort. However, this shortcoming is unlikely to have affected the reported incidence of recurrence or other complications in this study, as patients with complications such as seroma or infection are likely to have returned to our centre for review and this would thereby have been captured in our medical records.

Our study suggests that a general hospital with strict protocols and teaching methodologies can achieve outcomes for inguinal hernia repair that are comparable to those from dedicated hernia centres. It may be possible to improve the results of inguinal hernia repair by realigning clinical services at general hospitals, aiming to increase the experience of individual surgeons, as well as enhancing pre- and postoperative care of patients with inguinal hernia.

\section{REFERENCES}

1. Bay-Nielsen M, Kehlet H, Strand L, et al. Quality assessment of 26,304 herniorrhaphies in Denmark: a prospective nationwide study. Lancet 2001; 358:1124-8.

2. Flum DR, Horvath K, Koepsell T. Have outcomes of incisional hernia repair improved with time? A population-based analysis. Ann Surg 2003; 237:129-35.

3. Jansen $P L$, Klinge $U$, Jansen $M$, Junge $K$. Risk factors for early recurrence after inguinal hernia repair. BMC Surg 2009; 9:18.

4. Butters M, Redecke J, Köninger J. Long-term results of a randomized clinical trial of Shouldice, Lichtenstein and transabdominal preperitoneal hernia repairs. Br J Surg 2007; 94:562-5.

5. Kingsnorth AN, Bowley DM, Porter C. A prospective study of 1000 
hernias: results of the Plymouth Hernia Service. Ann R Coll Surg Engl 2003; 85:18-22.

6. The MRC Laparoscopic Groin Hernia Trial Group. Laparoscopic versus open repair of groin hernia: a randomised comparison. Lancet 1999; 354:185-90.

7. Cunningham J, Temple WJ, Mitchell $P$, et al. Cooperative hernia study. Pain in the postrepair patient. Ann Surg 1996; 224:598-602.

8. Jenkins JT, O’Dwyer PJ. Inguinal hernias. BMJ 2008; 336:269-72.

9. Finley RK Jr, Miller SF, Jones LM. Elimination of urinary retention following inguinal herniorrhaphy. Am Surg 1991; 57:486-8.

10. Koch CA, Grinberg GG, Farley DR. Incidence and risk factors for urinary retention after endoscopic hernia repair. Am J Surg 2006; 191:381-5.

11. Beldi G, Haupt N, Ipaktchi R, Wagner M, Candinas D. Postoperative hypoesthesia and pain: qualitative assessment after open and laparoscopic inguinal hernia repair. Surg Endosc 2008; 22:129-33.

12. Forte A, D'Urso A, Gallinaro LS, et al. [Complications of inguinal hernia repair]. G Chir 2002; 23:88-92. Italian.

13. Amid PK, Shulman AG, Lichtenstein IL. Open "tension-free" repair of inguinal hernias: the Lichtenstein technique. Eur J Surg 1996; 162:447-53.

14. Kurzer M, Belsham PA, Kark AE. The Lichtenstein repair for groin hernias. Surg Clin North Am 2003; 83:1099-117.

15. Shouldice EB. The Shouldice repair for groin hernias. Surg Clin North Am 2003; 83:1163-87.

16. Glassow F. The Shouldice Hospital technique. Int Surg 1986; 71:148-53.

17. Alfieri S, Amid PK, Campanelli G, et al. International guidelines for prevention and management of post-operative chronic pain following inguinal hernia surgery. Hernia 2011; 15:239-49.

18. WHO Expert Consultation. Appropriate body-mass index for Asian populations and its implications for policy and intervention strategies. Lancet 2004; 363:157-63.

19. NYU Langone Medical Center Division of General Surgery. Pantaloon Hernias. In: NYU Langone Medical Center [online]. Available at: http://surgery.med.nyu.edu/general/patient-care/hernias/types-hernia/ pantaloon-hernias. Accessed February 24, 2013.

20. Rosemar A, Angerås U, Rosengren A, Nordin P. Effect of body mass index on groin hernia surgery. Ann Surg 2010; 252:397-401.

21. Sorensen $L T$, Friis $E$, Jorgensen $T$, et al. Smoking is a risk factor for recurrence of groin hernia. World J Surg 2002; 26:397-400.

22. Junge $K$, Rosch $R$, Klinge $U$, et al. Risk factors related to recurrence in inguinal hernia repair: a retrospective analysis. Hernia 2006; 10:309-15.

23. Neumayer LA, Gawande AA, Wang J, et al. Proficiency of surgeons in inguinal hernia repair: effect of experience and age. Ann Surg 2005; 242:344-8.

24. Houghton IT, Aun CS, Gin T, Lau JT. Inter-ethnic differences in postoperative pethidine requirements. Anaesth Intensive Care 1992; 20:52-5.

25. O'Reilly EA, Burke JP, O'Connell PR. A meta-analysis of surgical morbidity and recurrence after laparoscopic and open repair of primary unilateral inguinal hernia. Ann Surg 2012; 255:846-53.

26. McCormack K, Scott NW, Go PM, et al. Laparoscopic techniques versus open techniques for inguinal hernia repair. Cochrane Database Syst Rev 2003; (1):CD001785. 